\title{
A NOVEL OPTIMIZATION MODEL FOR SIMULTANEOUS COST-RISK REDUCTION IN MULTI-SUPPLIERS JUST-IN-TIME SYSTEMS
}

\author{
${ }^{1,2}$ Faraj El Dabee, ${ }^{1}$ Romeo Marian and ${ }^{1}$ Yousef Amer \\ ${ }^{1}$ School of Engineering, University of South Australia, Adelaide, Australia \\ ${ }^{2}$ Department of Mechanical Engineering, Faculty of Engineering, University of Elmergib, Al-Khoms, Libya
}

Received 2013-04-12, Revised 2013-07-16; Accepted 2013-07-19

\begin{abstract}
In today's competitive global markets, Just-in-Time (JIT) is one of the main lean manufacturing approaches. It is used in organizations to improve performance and reduce costs and as a strategic core capability to ensure their market position. However, using JIT tightly couples various functions of the Supply Chain and increases the risk of propagating disruptions through the entire system. This study presents an ordering strategy for the supply of raw materials to the production system to meet customer satisfaction. A general model for cost-risk reduction is developed embracing multiple external and local backup suppliers. The outcomes from this model will be used to obtimise the simultaneous cost/risk reduction within JIT systems. The effectiveness of the developed model will be validated using a simplified example.
\end{abstract}

Keywords: Lean Manufacturing, Just-In-Time (JIT), Production System, Cost-Risk Reduction, Model, External Supplier, Local Backup Supplier, Optimization, Genetic Algorithm (GA)

\section{INTRODUCTION}

Recently, many organisations within the supply chain environment have implemented a JIT approach to increase their efficiency and to ensure their position in the competitive global marketplace (Canel and Khumawala, 2001; Ho and Kao, 2013). JIT as a lean manufacturing technique can be used to improve the quality of organisations and reduce product cost by eliminating all production facility waste and non-value added activities (Fahimnia et al., 2009). Waste may be defined as "anything other than the minimum amounts of resources, which are essential to add value to the product" (Rawabdeh, 2005). Typically, JIT focuses on purchasing and manufacturing the items that belong to the products consumed immediately (Ho and Kao, 2013). Successful implementation of JIT requires effective cooperation between suppliers and manufacturers due to small lot size delivery and inbound cost reduction (Chen and Sarker, 2009).
Globally, many organisations have incorporated JIT techniques in their processes to achieve their goals. However, some have ignored certain significant risks arising from implementing JIT. These risks potentially affect their processes by disrupting all supply chain parties involved (El Dabee et al., 2013a). For example, in 2011, businesses were drastically affected by natural disasters-the Japanese earthquake and tsunami and the floods in Thailand due to (BW, 2011; Krausmann and Cruz, 2013). As a result of implementing lean manufacturing and JIT within these industries, this led to disruption of their processes and of the whole supply chain. Therefore, a lack of any specific tool that can be utilised to achieve a simultaneous cost-risk reduction leads to significant problems for businesses. The main problem can be stated as the relation between the reduction of costs and the increase of risks arising from this reduction.

The goal of this study is to develop a mathematical model for simultaneously reducing the total cost of the final product and the potential risk when implementing

Corresponding Author: Faraj El Dabee, School of Engineering, University of South Australia, Adelaide, Australia 
JIT systems. The main objective is to ascertain an optimal ordering strategy for procuring raw materials for the production systems using multi-external and local backup suppliers. This strategy is essential in case of the occurrence of unforeseen disruptions occurring, such as natural and man-made disasters and economic crises in order to achieve a high product quality and total financial and operational actions within the supply chain.

The rest of this paper is organised as follows: Section 2 presents a review of research on JIT, cost and risk modelling. Section 3 presents the materials and methods, which incorporating the problem description, model notations, assumptions, parameters, decision variables, formulation and the testing of the developed model with a simplified example with which to evaluate the performance of the model. Section 4 discusses the results, which includes the model including verification of the model, further analysis of the results using different case examples of disruptions and randomly selected case of disruption occurrence using different levels of decision variables. Finally, section 5 summarises and concludes this paper.

\subsection{An Overview of JIT Modelling}

Just-In-Time (JIT) is a manufacturing pull system, which can be used for planning and controlling operations, in order to produce and supply the required products at the correct place, when they are required for use and in the required order-quantities (Hokoma et al., 2008; Monden, 2000). The main principles of JIT include: high quality, small lot sizes and regular deliveries in short lead times, close contact with suppliers (Hokoma et al., 2010). Using JIT in manufacturing reduces waste whilst increasing productivity, efficiency, profit and customer satisfaction (Li et al., 2000). Some critical principles are used for implementing JIT systems successfully such as people involvement, training and education, supplier relations, waste elimination, Kanban or pull system, uninterrupted work flow and total quality control. JIT is a critical tool for managing the external activities associated with an organisation including purchasing and distribution. It includes three elements, which are JIT production, JIT distribution and JIT purchasing (Tourki, 2010).

An integrated JIT lot-splitting model is developed to address the need for integration between the buyer and vendor for JIT system implementation. The developed model can minimise the cost impact on both buyer and vendor compared with the current approach in a simple JIT environment (Ha and Kim, 1997). Jaggi and Arneja
(2011) developed a periodic inventory model to reduce the lead time and setup cost under a normal interval of demand distribution. It is concluded that although the setup cost is high, the predicted total cost of running inventory system will be minimised. Also, Ho and Kao (2013) developed an innovative model for integrating the reduction of inventory and wastes within a JIT supply chain with a single buyer and a single vendor. They proved that by using the developed model, the expected total annual costs can be calculated easily.

In recent times, researchers have focused on specific model types such as an economic quantity model using a JIT approach for ordering raw materials and shipping processes for production systems. Different models can minimise the level of cost and risk in the case of JIT systems. For example, one such model type that can be used for achieving cost efficiency is the lot size reduction model. This model emphasises that by ensuring reduction in the lot size, it is possible to achieve a reduction with respect to the level of the cost required in performing the delivery of finished products to final consumers (Eldenburg, 2007). A mixed integer formulation for optimising a two-echelon supply network was developed. By implementing the developed model in a case study and considering all production costs, the effectiveness of this model was shown for real applications (Fahimnia et al., 2008).

A general cost model has been developed for procuring raw materials to the production system. It can be used to determine the batch size of the required products as well as the purchased quantity of raw materials in order to minimise the total cost that meet customer satisfaction (Khan and Sarker, 2002; Sarker and Khan, 1999). Yang and Pan (2004) investigate a JIT purchasing model where a single vendor supplies a product to a single purchaser. They presented an integrated inventory model, which minimised the sum of the ordering cost, holding cost, quality improvement and crashing cost by optimising the order quantity, lead time, process quality and the number of deliveries to provide a lower total cost, higher quality, smaller lot size and shorter lead time. Therefore, applying JIT methods such as small lot size in organisations, leads to time reduction and quality improvement having a significant impact enabling JIT purchasing to achieve their goals. Also, Lababidi et al. (2004) developed an optimization model for the petrochemical company supply chain operating under uncertain operating and economic conditions. This model was tested on a typical petrochemical firm to produce different grades of polyethylene using two reactors at a single location. The model determined the optimum production 
volumes that reduce the total costs of raw material procurement and transportation.

As systems become increasingly integrated, any disruption cannot be arrested in the functional area of origin and is consequently propagated throughout the production and distribution system. The reduction of waste (muda), as inventory or extra production capacity, exposes adjacent activities and may affect the whole supply chain. A higher lot size unnecessarily increases cost and some components of risk, while reducing others. Consequently, the lot size risk reduction model can be used to ensure an optimal lot size and thereby, efficient management of risk from the lot size is ultimately possible, achieving cost efficiencies. Simchi-Levi et al. (2002) emphasise the risks associated with a JIT system in cases of unforeseen disasters disrupting supply chain similar to those experienced by some auto manufacturers following Sept. 11, 2001. They emphasise that sharing risks throughout supply chain parties has a significant impact on them. An operation model might be used for JIT scheduling which explains each and every process included in the JIT system. Therefore, by identifying the stages of JIT systems, necessary actions can be taken to achieve cost efficiency in their operation (An and Fromm, 2005). Tomlin (2009) assesses 12 possible approaches to disruption management in the context of a two-product newsvendor. Some features of the organisation, its supplier(s) and its products such as supplier reliability and supplier failure correlation were investigated. Common dual sourcing can protect an organisation from any disruptive impacts when deliveries are received from different suppliers if one supplier is disrupted.

Carneiro et al. (2010) developed a two-stage stochastic model to optimise investment portfolios in the event of uncertainties occurring. This model was deployed within six large refineries in Brazil adopting the Conditional Value-at-Risk (CVaR) to minimise the Expected Net Present Value (ENPV) in the supply chain. Jose (2011) explains how risk management sources in a project's innovation can be better managed through a modelling process. He applies the risk management process on a specific case using a general innovation model to the risk creation parameters. An approach for considering a cost-risk balanced process to manage the scarce water resources under uncertain conditions was proposed. A new technique was modelled regarding a reoptimization phase that permits users to organise emergency strategies by adopting the barycentric value as a new target, which resulted in drastic risk reduction in resource delivery (Gaivoronski et al., 2012). A mathematical model to reduce the total cost of the products and at the same time to reduce the risks arising from this cost reduction within production systems was developed. Raw materials are procured from external suppliers to produce the final product in the production system. It was concluded that comparing the use of a JIT system with the use of a specific amount of inventory from in-house stock during a limited period of time had a direct impact on the production system (El Dabee et al., 2012; 2013b).

All models of JIT systems presented above reduced either cost or risk independently. It is clear that risks have a significant impact in organisations' performance, which leads to increase their total costs and at the same time reduces their efficiency. Therefore, risks should be assessed by identifying, evaluating and measuring them, to reduce the undesired effects they cause within organisations and the JIT models have costs and risks considered simultaneously.

\section{MATERIALS AND METHODS}

All problem statement, assumptions, notations, decision variables, parameters and mathematical formulations will be described.

\subsection{Problem Description}

In this study, a general cost model is developed for simultaneously reducing the cost and risks effect in JIT systems. This model incorporates three main parties, which are supplier, manufacturer and end user. It is assumed that a distribution network consists of multiple external suppliers used to supply raw materials to the production system to produce the final product. This assumption is due to pricing variations for the same product in different markets. The materials are transported from different manufacturers to the production system, which in turn produce the final product for sale to wholesale or retail outlets. Also, the raw materials are replenished instantaneously to the production system to meet JIT operation. The products are delivered to the end customers with no holding capacity to store the products. They may include wholesalers or retailers.

Many risks may result from the occurrence of unforeseen disruptions such as natural and man-made disasters and economic crises affecting external suppliers. All of them have a significant impact on the production facility and the entire supply chain as well. To avoid the impact of these risks, it is assumed that during a time of disruption, the production system can procure its raw materials required to produce the final product from a 
local backup supplier at a higher price but with low risk and in a short lead time (El Dabee et al., 2013a).

The model also considers scenarios where orders for a set amount of raw materials are shipped by both suppliers on a fixed amount of raw materials in a standard case of customer requirements using different transportation modes (waterways, railways, roadways and airways). The appropriate transportation mode can be selected depending on some key criteria such as the lead time and the transportation cost needed to bring raw materials into the production system.

\subsection{Notations}

The following notations are used in the proposed model:

$\mathrm{C}_{\mathrm{T}}$ : Total cost required to produce one product in monetary unit (MU);

$\mathrm{C}_{\mathrm{M}}$ : Raw material cost required for producing one product (MU);

$\mathrm{C}_{\mathrm{O}}$ : Ordering cost of raw materials (MU);

$\mathrm{C}_{\mathrm{H}}$ : Holding cost of raw materials within the production system stores (MU);

$\mathrm{C}_{\mathrm{R}}$ : Risk cost arising from disruption occurrence (MU);

$\mathrm{C}_{\mathrm{tr}}$ : Transportation cost for delivering raw materials to the production system (MU);

$\mathrm{C}_{\mathrm{P}}$ : The purchasing cost of raw materials required to produce the product (MU);

$\mathrm{C}_{\mathrm{U}}$ : Utilities cost of the final product (MU);

$\mathrm{C}_{\mathrm{D}}$ : Duties cost arising from procuring raw material from an external supplier (MU);

$\mathrm{TP}_{\mathrm{i}}$ : Transfer price required for procuring raw material $\mathrm{i}$ from an external supplier i (MU);

$\mathrm{S}$ : Origin of ordered raw materials;

v: Destination of required raw materials;

$\mathrm{m}_{\mathrm{i}}$ : Transportation mode for transporting raw material i to its customer;

$\mathrm{N}_{\mathrm{T}}$ : Number of transportation modes used for shipping raw materials to the production system (unit);

$\mathrm{N}_{\mathrm{K}}$ : Number of raw materials ordered to the production system in each patch (unit);

$\mathrm{N}_{\mathrm{LT}}$ : Number of days required to provide the production system with raw materials in each patch (unit);

$\mathrm{S}_{\mathrm{Ej}}$ : Raw material external supplier $\mathrm{j}$;

$\mathrm{S}_{\mathrm{LBs}}$ : Raw material local backup supplier s;

IF: Indicator function for duty with a value 1 or 0.1 if the supplier and the production facility are in the same country and 0 otherwise;

$\mathrm{M}_{\mathrm{i}}$ : Raw material types required in producing one unit of product $i$;
$\mathrm{H}_{\mathrm{k}}$ : Expected risk $\mathrm{k}$ occurs on the supply chain production system;

LH: Likelihood of occurrence for risk in the supply chain

I: Impact of risk occurrence in the supply chain.

\subsection{Model Assumptions}

The model formulation is based on the following assumptions:

- The ordering cost of raw materials is a fixed rate for each order regardless of the order size

- The utilities cost of the final product is a percentage of total cost of the product that can be changed by the inventory batch size

- The final product price is a fixed rate regardless of the inventory batch size

- The raw materials are supplied by the regular external supplier if there is no disruption occurs

- The raw materials can be purchased from the local backup supplier when one or more of the regular external suppliers have disruption

- The cost of raw materials procured from local backup supplier $\mathrm{S}_{\mathrm{LBi}}$ is a percentage of their cost when they are purchased from the regular external supplier $\mathrm{S}_{\mathrm{Ei}}$ depending on its reliability $\left(\mathrm{R}_{\mathrm{SLBj}}\right)$

- The transportation cost is proportional to the transportation distances and the used transportation modes

- The worker cost required for producing the final product per time unit is a fixed rate per time unit

- The risk cost arising from the likelihood of risk occurrence is a percentage rate depending on its impact on the production system

- The duties cost is incurred if raw materials are supplied by external supplier $\mathrm{S}_{\mathrm{Ei}}$

- The transfer price required to procure raw material from the regular external supplier $\mathrm{S}_{\mathrm{Ei}}$ is a percentage of its total cost $\mathrm{C}_{\mathrm{RM}}$

- The reliability of local backup supplier j reflects the availability for supplying raw materials at the planned time if the regular external supplier has disruption (0- 1)

- Each external and local backup supplier is able to supply some of raw material types

- The purchasing price for raw materials may vary from supplier to supplier depending on the negotiations, order sizes, discounts, historical relationships

\subsection{Model Parameters}

Parameters are considered as the input data that necessary for a system. They are variables with fixed 
given values as inputs to the optimization system (MohdLair, 2008). In this study, the parameters used for reducing the costs of products and the risks arising from these costs in JIT systems are:

$\mathrm{N}_{\mathrm{O}}$ : $\quad$ Number of operations required for producing one product (unit);

$\mathrm{N}_{\mathrm{P}}$ : Number of parts required to produce one product (unit);

$\mathrm{N}_{\mathrm{SE}}$ : Number of external suppliers used for supplying raw materials to the production system (unit);

$\mathrm{N}_{\mathrm{SLB}}$ : Number of local suppliers used for supplying raw materials to the production system (unit);

$\mathrm{N}_{\mathrm{W}}$ : Number of workers required to produce one product (unit);

$\mathrm{C}_{\mathrm{UO}}$ : Ordering cost of raw materials for the final product (MU);

$\mathrm{C}_{\mathrm{UH}}$ : Holding cost of raw materials of each final product in the production system warehouse (MU/ day);

$\mathrm{C}_{\mathrm{UMi}}$ : Unit cost of the raw material $\mathrm{i}$ at the beginning of each cycle (MU);

$\mathrm{d}_{\mathrm{RM}}$ : Daily demand of raw materials required to meet customer satisfaction (unit);

$\% \mathrm{~d}_{\mathrm{RM}}$ : Daily demand percentage of raw materials required to meet customer satisfaction (unit);

$\mathrm{N}_{\mathrm{WD}}$ : $\quad$ Number of working days per week (unit);

$\mathrm{h}$ : Operation time required to produce a product (hr);

$\mathrm{C}_{\mathrm{L}}$ : $\quad$ Labor cost rate per time in one operation (MU/hr);

$\mathrm{C}_{\text {TOmang: }}$ : Total managerial ordering cost per order (MU);

$\mathrm{C}_{\mathrm{THmang}}$ : Total managerial holding cost for keeping raw materials to produce final product during the lead time duration;

$\mathrm{N}_{\mathrm{wks}}$ : Number of weeks required to keep raw materials in warehouses (unit);

SF: $\quad$ Storage factor for keeping raw materials in the warehouse;

OF: $\quad$ Ordering factor for procuring each order from the supplier;

\%Util: Utilities cost percentage of the final product (MU);

$\mathrm{t}_{\mathrm{p}}$ : $\quad$ Raw material cost percentage incurred for procuring raw material $\mathrm{i}$ from an external supplier j (MU);

$\mathrm{T}_{\mathrm{Sj}, \mathrm{v}, \mathrm{m}}$ : Tensor for transportation cost per critical measurement (MU);

$\mathrm{t}_{\mathrm{m}}$ : Critical transportation measurement of raw materials shipped using transportation mode $\mathrm{m}$;
$\% \mathrm{~V}: \quad$ Volume percentage value required for transporting raw materials to their customer;

$\mathrm{N}_{\mathrm{h}}$ : $\quad$ Number of working hours per day (hr);

$\mathrm{D}_{\mathrm{i}}$ : $\quad$ Duty rate $(\%)$ per price of raw material $\mathrm{i}$ supplied by external supplier j (MU);

\%sale: Sales percentage value offered from selling extra raw materials during the same order;

$\mathrm{N}_{\mathrm{RM}}$ : Number of raw materials supplied to the production system (unit);

$\mathrm{R}_{\mathrm{SLBS}}$ : Reliability of local backup supplier $\mathrm{s}$ for supplying raw materials at the planned time;

$\mathrm{R}_{\mathrm{SEj}}$ : Reliability of external supplier $\mathrm{j}$ for supplying raw materials at the planned time;

$\mathrm{C}_{\mathrm{W}}$ : Worker cost required for producing the final product per time unit (MU);

$\mathrm{P}_{\mathrm{i}}$ : $\quad$ Final price per unit of final product $\mathrm{i}$ sold to the customer (MU);

\%TRS: Total risk score percentage value.

\subsection{Model Decision Variables}

Decision variables are the variables that represent the design method outputs of the model. They are also called controlled factors. This means that any change of their values may change the results of the model outputs. The decision variables are:

LT: Lead-time taken between placing and receiving the placed order (day);

$\mathrm{Q}_{\mathrm{M}}$ : The quantity of raw material $\mathrm{i}$ ordered in each patch required to produce the final product per week (unit);

$\mathrm{d}_{\mathrm{P}}$ : Customer demand for the final product per day (unit);

$\mathrm{t}_{\mathrm{m}}$ : Critical transportation measurement of raw materials shipped using transportation mode $\mathrm{m}$.

\subsection{Model Formulation Description}

A general cost model is developed considering the point of view supplier of raw material. This model is utilised to ascertain an optimal ordering strategy for obtaining the batch size of raw materials using both external and local backup suppliers to minimise the total cost of the final products and its risk effect in JIT systems. It is built to determine the total cost of producing the final product within production systems. The total cost of this product can be found by Equation (1):

$\mathrm{C}_{\mathrm{T}}=\mathrm{C}_{\mathrm{RM}}+\mathrm{C}_{\mathrm{W}}+\mathrm{C}_{\mathrm{U}}+\mathrm{C}_{\mathrm{R}}$ 
Each component of the total cost of the final product is described as follows:

\subsubsection{Raw Material Cost $\left(\mathrm{C}_{\mathrm{RM}}\right)$}

Raw material cost is the cost of raw materials used to produce the final product in the production system. The inflation rate in both producing and using countries has a significant impact on this cost (Canel and Khumawala, 2001). In this research, raw material cost includes the ordering cost $\mathrm{C}_{\mathrm{O}}$, holding $\cos t \mathrm{C}_{\mathrm{H}}$, purchasing cost $\mathrm{C}_{\mathrm{P}}$, transportation cost $\mathrm{C}_{\mathrm{tr}}$, duties cost $\mathrm{C}_{\mathrm{D}}$ and transfer price cost TP. Therefore, it can be calculated as:

$$
\mathrm{C}_{\mathrm{RM}}=\mathrm{C}_{\mathrm{O}}+\mathrm{C}_{\mathrm{H}}+\mathrm{C}_{\mathrm{P}}+\mathrm{C}_{\mathrm{tr}}+\mathrm{C}_{\mathrm{D}}+\mathrm{TP}
$$

Equation 2 can only be used if the regular external supplier supplies raw materials to the production system. However, in the case where the production system procures its raw materials from the local backup supplier, the raw material cost just includes $\mathrm{C}_{\mathrm{O}}, \mathrm{C}_{\mathrm{H}}, \mathrm{C}_{\mathrm{P}}$ and $\mathrm{C}_{\mathrm{tr}}$. The production system does not incur any of $\mathrm{C}_{\mathrm{D}}$ and $\mathrm{TP}$. Therefore, $\mathrm{C}_{\mathrm{RM}}$ can be calculated as Equation (3):

$$
\mathrm{C}_{\mathrm{RM}}=\mathrm{C}_{\mathrm{O}}+\mathrm{C}_{\mathrm{H}}+\mathrm{C}_{\mathrm{P}}+\mathrm{C}_{\mathrm{tr}}
$$

\subsubsection{Ordering $\operatorname{Cost}\left(\mathrm{C}_{0}\right)$}

Ordering costs are the cost of ordering and receiving an amount of raw materials each order. These costs include determining how much is required, preparing invoices, inspecting goods upon arrival for quality and quantity against shipping lists and moving the goods to temporary storage. Generally, they are expressed as a fixed value per order, regardless of the order batch size (Chopra and Meindl, 2010).

Therefore, $C_{O}$ can be calculated as Equation (4):

$$
\mathrm{C}_{\mathrm{UOj}}=\frac{\mathrm{C}_{\mathrm{TOmang}}}{\% \mathrm{~d}_{\mathrm{RM}} \times \mathrm{LT}_{\mathrm{j}}}
$$

$\mathrm{j}=1,2,3, \ldots, \mathrm{N}_{\mathrm{SE}}$

Then, $\% \mathrm{~d}_{\mathrm{RM}}$ equals Equation (5):

$$
\% \mathrm{~d}_{\mathrm{RM}}=\frac{\mathrm{d}_{\mathrm{P}}}{\mathrm{d}_{\mathrm{RM}}}
$$

For an external supplier Equation (6):

$$
\mathrm{C}_{\mathrm{O}}=\mathrm{C}_{\mathrm{UO}} \times \mathrm{OF}
$$

where, Equation (7):

$$
\mathrm{C}_{\mathrm{UO}}=\sum_{\mathrm{j}=1}^{\mathrm{N}_{\mathrm{SE}}} \mathrm{C}_{\mathrm{UOj}}
$$

Therefore Equation (8):

$$
\mathrm{C}_{\mathrm{O}}=\sum_{\mathrm{j}=1}^{\mathrm{N}_{\mathrm{SE}}} \mathrm{C}_{\mathrm{UOj}} \times \mathrm{OF}
$$

However, if the production system procures its raw materials from local supplier, then Equation (9):

$$
\mathrm{C}_{\mathrm{UO}}=\frac{\mathrm{C}_{\mathrm{TOmang}}}{\% \mathrm{~d}_{\mathrm{RM}} \times \mathrm{LT}_{\mathrm{s}}}
$$

$\mathrm{S}=1,2,3, \ldots, \mathrm{N}_{\mathrm{SLB}}$.

Thus Equation (10):

$\mathrm{C}_{\mathrm{UO}}=\sum_{\mathrm{S}=1}^{\mathrm{N}_{\mathrm{SLB}}} \mathrm{C}_{\mathrm{UOS}}$

Therefore, the ordering cost of raw materials procured from local suppliers equals Equation (11):

$$
\mathrm{C}_{\mathrm{O}}=\sum_{\mathrm{S}=1}^{\mathrm{N}_{\mathrm{SLB}}} \mathrm{C}_{\mathrm{UOS}} \times \mathrm{OF}
$$

\subsubsection{Holding $\operatorname{Cost}\left(\mathrm{C}_{\mathrm{H}}\right)$}

Holding cost is the cost of keeping one unit of raw materials in warehouses for a specified time period (Chopra and Meindl, 2010). In this study, it includes insurance, depreciation, obsolescence, deterioration, spoilage, breakage and warehousing costs (heat, light, rent and security).

The rate of $\mathrm{C}_{\mathrm{H}}$ if the production system procures its raw materials from an external supplier equals Equation (12):

$$
\mathrm{C}_{\mathrm{UHj}}=\frac{\mathrm{C}_{\mathrm{THmang}}}{\mathrm{N}_{\mathrm{RM}}}
$$

Therefore Equation (13):

$$
\begin{aligned}
& \mathrm{C}_{\mathrm{H}}=\sum_{\mathrm{i}=1}^{\mathrm{N}_{\mathrm{P}}} \sum_{\mathrm{j}=1}^{\mathrm{N}_{\mathrm{SE}}}\left(\mathrm{C}_{\mathrm{UHj}}\right)_{\mathrm{j}} \times \% \mathrm{~d}_{\mathrm{RM}} \times\left(\mathrm{LT}_{\mathrm{j}}+\mathrm{SF}\right) \\
& \mathrm{i}=1,2,3, \ldots ., \mathrm{N}_{\mathrm{P} .}
\end{aligned}
$$

However, if a local backup supplier supplies raw materials to the production facility, then Equation (14):

$$
\mathrm{C}_{\mathrm{H}}=\sum_{\mathrm{i}=1}^{\mathrm{N}_{\mathrm{P}}} \sum_{\mathrm{S}=1}^{\mathrm{N}_{\mathrm{SLB}}}\left(\mathrm{C}_{\mathrm{UHj}}\right)_{\mathrm{S}} \times \% \mathrm{~d}_{\mathrm{RM}} \times\left(\mathrm{LT}_{\mathrm{S}}+\mathrm{SF}\right)
$$




\subsubsection{Purchasing $\operatorname{Cost}\left(\mathrm{C}_{\mathrm{P}}\right)$}

Purchasing cost is the cost of goods acquired from suppliers required to produce the final product in the production facility. In this research, it is considered as the unit cost of raw material at the beginning of that cycle $\left(\mathrm{C}_{\mathrm{UM}}\right)$.

For an external supplier, $\mathrm{C}_{\mathrm{P}}$ can be calculated as Equation (15):

$$
\left.\mathrm{C}_{\mathrm{UMSEj}}=\% \text { sale } \times \mathrm{C}_{\mathrm{UPi}}\right)_{\mathrm{j}}
$$

Then Equation (16):

$$
\mathrm{C}_{\mathrm{P}}=\sum_{\mathrm{i}=1}^{\mathrm{N}_{\mathrm{P}}} \sum_{\mathrm{j}=1}^{\mathrm{N}_{\mathrm{SE}}}\left(\mathrm{C}_{\mathrm{UMSEi}}\right)_{\mathrm{j}}
$$

However, if raw materials are procured from a local backup supplier, $\mathrm{C}_{\mathrm{P}}$ equals Equation (17):

$$
\left.\mathrm{C}_{\mathrm{UMSLBS}}=\% \text { sale } \times \mathrm{C}_{\mathrm{UPi}}\right)_{\mathrm{S}} \times \mathrm{R}_{\mathrm{SLBS}}
$$

Therefore Equation (18):

$$
\mathrm{C}_{\mathrm{P}}=\sum_{\mathrm{i}=1}^{\mathrm{N}_{\mathrm{P}}} \sum_{\mathrm{S}=1}^{\mathrm{N}_{\mathrm{SLB}}}\left(\mathrm{C}_{\mathrm{UMSLBi}}\right)_{\mathrm{S}}
$$

\subsubsection{Transportation $\operatorname{Cost}\left(\mathrm{C}_{\mathrm{tr}}\right)$}

Transportation cost represents the per unit transportation cost for transporting raw materials from a supplier to the production system in time period t. This cost varies depending on the access from the potential location to the production facility. This research assumes that the transportation of raw materials is conducted in batches that meet customer satisfaction.

$\mathrm{C}_{\text {tr }}$ as a component of $\mathrm{C}_{\mathrm{RM}}$ can be calculated as:

For external supplier Equation (19):

$\mathrm{C}_{\mathrm{tr}}=\sum_{\mathrm{j}=1}^{\mathrm{N}_{\mathrm{SE}}} \sum_{\mathrm{l}=1}^{\mathrm{N}_{\mathrm{T}}} \sum_{\mathrm{Z}=1}^{\mathrm{N}_{\mathrm{RM}}} \mathrm{T}_{\mathrm{SEj}, \mathrm{V}, \mathrm{m}} \times \mathrm{t}_{\mathrm{ml}} \times \% \mathrm{~V}_{\mathrm{Z}}$

$1=1,2,3, \ldots ., \mathrm{N}_{\mathrm{T}}$ and $\mathrm{Z}=1,2,3, \ldots ., \mathrm{N}_{\mathrm{RM}}$.

Nevertheless, for a local backup supplier Equation (20):

$$
\mathrm{C}_{\mathrm{tr}}=\sum_{\mathrm{S}=1}^{\mathrm{N}_{\mathrm{SLB}}} \sum_{\mathrm{l}=1}^{\mathrm{N}_{\mathrm{T}}} \sum_{\mathrm{Z}=1}^{\mathrm{N}_{\mathrm{RM}}} \mathrm{T}_{\mathrm{SLBS}, \mathrm{V}, \mathrm{m}} \times \mathrm{t}_{\mathrm{ml}} \times \% \mathrm{~V}_{\mathrm{Z}}
$$

\subsubsection{Duties Cost $\left(C_{D}\right)$}

This is the tax incurred by importing goods from supplier in one country to a customer in another country. It is based on the value of goods or upon some criteria of the item such as weight and dimensions. This work considers $\mathrm{C}_{\mathrm{D}}$ as the cost arises from supplying raw materials by a regular external supplier $S_{\mathrm{Ej}}$ to the production system. It means that for local backup suppliers $S_{\mathrm{LBj}}$, there are no duties arising from supplying raw materials to the production system. It can be calculated as Equation (21):

$$
\begin{aligned}
& C_{D}=\sum_{i=1}^{N_{P}} \sum_{j=1}^{N_{S E}} C_{U P i}\left(1-I_{j}\right) \times D_{j} \\
& I F_{j}=0 \text { if } S_{j}=1, \text { otherwise } I F=1 .
\end{aligned}
$$

\subsubsection{Transfer Price Cost (TP)}

Transfer price is the per unit price of products and services to be charged among independent organisations (Chen, 2011). It is one of the most significant issues facing Multinational Companies (MNCs).

In this study, TP as a transfer price for procuring raw material from a regular external supplier $S_{E j}$ can be calculated as Equation (22):

$$
\mathrm{TP}=\sum_{\mathrm{j}=1}^{\mathrm{N}_{\mathrm{SE}}} \sum_{\mathrm{i}=1}^{\mathrm{N}_{\mathrm{P}}} \mathrm{tp}_{\mathrm{j}} \times \mathrm{C}_{\mathrm{UPi}}
$$

\subsubsection{Worker $\operatorname{Cost}\left(\mathrm{C}_{\mathrm{W}}\right)$}

Worker cost is the wages paid to the employee through performing certain duties in any organisation in a time unit. In this research, each operation requires an operational time $h_{i}$ (hours) and the time of producing one product is the sum of operational time of all operations. Therefore, $\mathrm{C}_{\mathrm{W}}$ is considered as the rate resulting from multiplying the cost of working time by the time required for producing the final product (hour), which can be calculated as follows Equation (23):

$$
\mathrm{C}_{\mathrm{W}}=\sum_{\mathrm{i}=1}^{\mathrm{N}_{\mathrm{P}}} \mathrm{C}_{\mathrm{Wi}}=\sum_{\mathrm{i}=1}^{\mathrm{N}_{\mathrm{P}}} \mathrm{C}_{\mathrm{Li}} \times \mathrm{h}_{\mathrm{i}}
$$

\subsubsection{Utilities Cost $\left(\mathrm{C}_{\mathrm{U}}\right)$}

Utilities cost is the cost arising from using the required utilities such as electricity, gas, heat, water and maintenance to produce final product in the production facility. This research considers $\mathrm{C}_{\mathrm{U}}$ as a raw material cost percentage of the final product. It equals Equation (24):

$$
\mathrm{C}_{\mathrm{U}}=\sum_{\mathrm{i}=1}^{\mathrm{N}_{\mathrm{P}}} \% \mathrm{C}_{\mathrm{RMi}}
$$


By considering $\mathrm{C}_{\mathrm{pt}}$ as the cost of raw materials used to produce one part of the final product, it is equal Equation (25):

$$
\mathrm{C}_{\mathrm{pt}}=\mathrm{C}_{\mathrm{O}}+\mathrm{C}_{\mathrm{H}}+\mathrm{C}_{\mathrm{P}}+\mathrm{C}_{\mathrm{tr}}+\mathrm{C}_{\mathrm{D}}+\mathrm{TP}+\mathrm{C}_{\mathrm{w}}+\mathrm{C}_{\mathrm{U}}
$$

\subsubsection{Risk Cost $\left(\mathrm{C}_{\mathrm{R}}\right)$}

Risk cost is the cost arising from the likelihood of any disruptive occurrence that might affect either one part or the whole system. These risks have a significant impact on the total cost of the system. In this research, each supplier has a different impact on the supply chain of the production system depending on its risk score.

Therefore, $C_{R}$ can be calculated by the following equation Equation (26):

$$
\mathrm{C}_{\mathrm{R}}=\sum_{\mathrm{i}=1}^{\mathrm{N}_{\mathrm{P}}} \% \mathrm{TRS}_{\mathrm{i}} \times \mathrm{C}_{\mathrm{Pt}_{\mathrm{i}}}=\sum_{\mathrm{i}=1}^{\mathrm{N}_{\mathrm{P}}} \frac{\mathrm{LH} \times \mathrm{I}}{\operatorname{Max}(\mathrm{LH} \times \mathrm{I})} \times \mathrm{C}_{\mathrm{Pt}_{\mathrm{i}}}
$$

\subsection{Simplified Example}

The proposed mathematical model has been tested with a simple assembly process for an electric motor with hollow shzaft. It uses multiple, identical operations to assemble 25 individual parts into the finished product $\left(N_{P}=25\right)$. The main components of this motor are illustrated in Fig. 1.

It is assumed that a production system purchases raw materials in a fixed lot size from eleven different regular external suppliers $\left(\mathrm{N}_{\mathrm{SE}}=11\right)$. These raw materials are delivered at a fixed interval of time when they are needed (JIT system). Parts 1, 2 and 4 are supplied by the supplier $\mathrm{S}_{\mathrm{E} 1}$, which need 24 days (LT) to arrive; Parts 3, 11 and 18 are procured from the supplier $\mathrm{S}_{\mathrm{E} 2}$, which require 32 days to arrive; Parts 5 and 10 are supplied by the supplier $\mathrm{S}_{\mathrm{E} 3}$, which need 18 days to arrive; Parts 6 and 7 are supplied by the supplier $\mathrm{S}_{\mathrm{E} 4}$, which require 38 days to arrive; Parts 8 and 9 are supplied by the supplier $S_{\mathrm{E} 5}$, which need 42 days to arrive; Parts 12 and 15 are procured from the supplier $\mathrm{S}_{\mathrm{E} 6}$, which require 28 days to arrive; Parts 13 and 14 are supplied by the supplier $\mathrm{S}_{\mathrm{E} 7}$, which need 35 days to arrive; Parts 17, 19 and 21 are supplied by the supplier $\mathrm{S}_{\mathrm{E} 8}$, which require 45 days to arrive; Parts 16 and 20 are supplied by the supplier $\mathrm{S}_{\mathrm{E} 9}$, which need 20 days to arrive; Parts 22,23 and 25 are procured from the supplier $S_{\mathrm{E} 10}$, which require 28 days to arrive; and Part 25 is supplied by the supplier $\mathrm{S}_{\mathrm{E} 11}$, which take 21 days to arrive. The production system includes 5 operations conducted by five workers $\left(\mathrm{W}_{1}, \mathrm{~W}_{2}\right.$, $\mathrm{W}_{3}, \mathrm{~W}_{4}$ and $\mathrm{W}_{5}$ respectively). The number of working hours $\mathrm{N}_{\mathrm{h}}$ is $8 \mathrm{~h}$ a day for 5 days per week. Each worker has a fixed wage $\mathrm{C}_{\mathrm{Wi}}$ valued 14 Monetary Unit (MU)/hour.
Operation 1 assembles Parts 6, 7, 8, 9 and 20 and transfers them to Operation 2, which assembles Parts 5, 10, 11, 12 and 13 and then transfers them to Operation 3. Operation 3 assembles Parts 16, 17, 18, 19, 21, 22, 23, 24 and 25 and then transfer to Operation 4. Operation 4 assembles Parts 1 , $2,3,4,13,14$ and 15 and finally transfers the product to Operation 5, which tests and keeps the final product in boxes and then sends it to the sales department. It is assumed that the utilities cost $\mathrm{C}_{\mathrm{U}}$ is equal to $10 \%$ of the raw material cost. Furthermore, it is assumed that in the case of one or more of external suppliers suffering disruption, the production system can procure its raw materials from seven local backup suppliers $\left(\mathrm{N}_{\mathrm{SLB}}=7\right)$ with a higher cost but with a low risk and in a short lead time. In this case, Parts 1, 2 and 4 can be supplied by the supplier $S_{\mathrm{LB} 1}$ in 4 days; Parts 3, 11 and 18 can be procured from the supplier $\mathrm{S}_{\mathrm{LB} 2}$ due to 6 days; Parts 5,10, 16 and 20 can be supplied by the supplier $\mathrm{S}_{\mathrm{LB} 3}$ in 3 days; Parts $6,7,8$ and 9 can be supplied by the supplier $\mathrm{S}_{\mathrm{LB} 4}$ through 5 days; Parts 12 , 13,14 and 15 can be supplied by the supplier $S_{\mathrm{LB} 5}$ in 7 days; Parts 17, 19 and 21 can be procured from the supplier $\mathrm{S}_{\mathrm{LB} 6}$ due to 5 days; Finally, Parts 22, 23, 24 and 25 can be supplied by the supplier $S_{\mathrm{LB} 7}$ in 6 days. For any extra amount of raw materials procured from both of external and local suppliers, discounts are offered to the production system as shown in Table 1 and 2.

The production facility produces 70 units/day and it purchases raw materials from the different regular external suppliers $\mathrm{S}_{\mathrm{E}}$ (if no disruption occurs) and local backup supplier $S_{L B}$ (when one or more of the regular suppliers are disrupted). Each order depends on the lead time from each supplier. These order quantities can meet customer needs during a fixed interval of normal time. However, a time delay for the arrival of these materials to the production system punctually can cause many risk factors such as physical, social, legal, operational, economic and political factors. These factors can affect and disrupt the production system and all the supply chain parties. Therefore, the effects of these factors on the production facility are studied in this work as a case study. Finally, the end customer purchases the final product by 485 MU. Figure 2 illustrates the supply chain relating to for this production system.

The next step is to identify supply chain risks facing the production facility. Table 3 includes the main supply chain risks potentially facing the production/marketing of this product and their impacts within the production system. The risk identification was done from the perception of identifying the effect of the disruption or change in demand has on this production facility. It can also be approached by investigating all possible root causes of supply chain issues. 


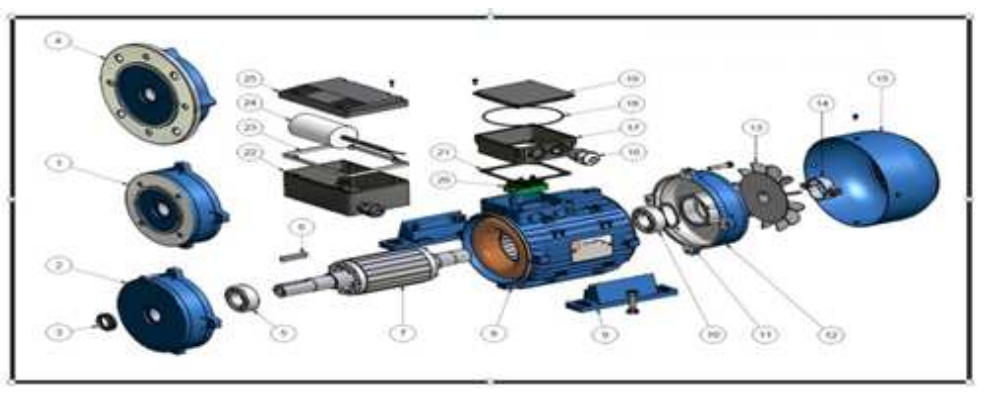

Fig. 1. Electric motor (Hollow Shaft)

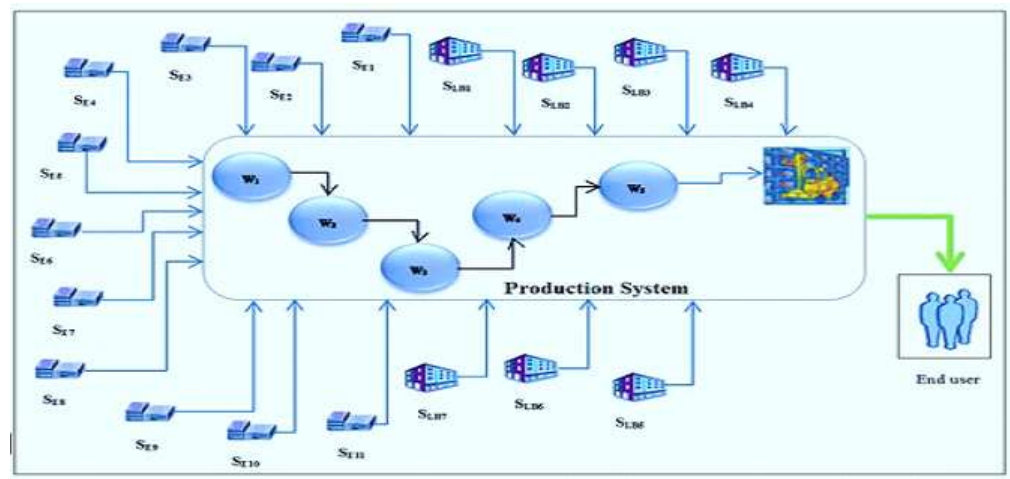

Fig. 2. The supply chain for the production system

Table 1. Discounts offered by external suppliers for purchasing extra raw materials

\begin{tabular}{|c|c|c|c|c|c|c|c|}
\hline \multirow[b]{2}{*}{ External supplier } & \multicolumn{7}{|c|}{ Discounts rate $(\%)$} \\
\hline & Week1 & Week2 & Week3 & Week4 & Week5 & Week6 & Week7 \\
\hline 1 & 95 & 90 & 85 & 80 & $\mathrm{x}$ & $\mathrm{x}$ & $\mathrm{x}$ \\
\hline 2 & 93 & 88 & 85 & 82 & 80 & $\mathrm{x}$ & $\mathrm{x}$ \\
\hline 3 & 95 & 90 & 85 & $\mathrm{x}$ & $\mathrm{x}$ & $\mathrm{x}$ & $\mathrm{x}$ \\
\hline 4 & 90 & 88 & 86 & 84 & 82 & 80 & $\mathrm{x}$ \\
\hline 5 & 95 & 92 & 90 & 88 & 86 & 84 & $\mathrm{x}$ \\
\hline 6 & 95 & 90 & 85 & 80 & $\mathrm{x}$ & $\mathrm{x}$ & $\mathrm{x}$ \\
\hline 7 & 95 & 91 & 88 & 86 & 85 & $\mathrm{x}$ & $\mathrm{x}$ \\
\hline 8 & 96 & 92 & 90 & 87 & 85 & 82 & 80 \\
\hline 9 & 95 & 90 & 85 & $\mathrm{x}$ & $\mathrm{x}$ & $\mathrm{x}$ & $\mathrm{x}$ \\
\hline 10 & 90 & 86 & 83 & 81 & $\mathrm{x}$ & $\mathrm{x}$ & $\mathrm{x}$ \\
\hline 11 & 95 & 92 & 90 & $\mathrm{x}$ & $\mathrm{x}$ & $\mathrm{x}$ & $\mathrm{x}$ \\
\hline
\end{tabular}

Table 2. Discounts offered by local backup suppliers for purchasing extra raw materials

Discounts rate $(\%)$

\begin{tabular}{llllllll} 
Local supplier & Week1 & Week2 & Week3 & Week4 & Week5 & Week6 & Week7 \\
\hline 1 & 95 & 90 & 85 & 80 & $\mathrm{x}$ & $\mathrm{x}$ & $\mathrm{x}$ \\
2 & 93 & 88 & 85 & 82 & 80 & $\mathrm{x}$ & $\mathrm{x}$ \\
3 & 95 & 90 & 85 & $\mathrm{x}$ & 82 & 80 & $\mathrm{x}$ \\
4 & 90 & 88 & 86 & 84 & 86 & 84 & $\mathrm{x}$ \\
5 & 96 & 92 & 90 & 88 & 85 & 82 & 80 \\
6 & 96 & 92 & 90 & 87 & 85 & $\mathrm{x}$ & $\mathrm{x}$ \\
7 & 95 & 91 & 88 & 86 & &
\end{tabular}


Table 3. Risk assessment of the electric motor production system

\begin{tabular}{|c|c|c|c|c|c|}
\hline Risk & Risk & $\begin{array}{l}\text { Product } \\
\text { effect }\end{array}$ & $\begin{array}{l}\text { Likelihood } \\
(1-5)\end{array}$ & $\begin{array}{l}\text { Impact } \\
(1-5)\end{array}$ & $\begin{array}{l}\% \text { total } \\
\text { risk score }\end{array}$ \\
\hline $\mathrm{H}_{1}$ & $\begin{array}{l}\text { Supplier } 1 \text { cannot supply raw materials on } \\
\text { the scheduled time or is destroyed by disasters. }\end{array}$ & Parts $1 \& 2$ & 1 & 2 & $8 \%$ \\
\hline $\mathrm{H}_{2}$ & $\begin{array}{l}\text { Supplier } 2 \text { cannot supply raw materials on the } \\
\text { scheduled time or is destroyed by disasters. }\end{array}$ & Parts $3 \& 4$ & 2 & 1 & $8 \%$ \\
\hline $\mathrm{H}_{3}$ & $\begin{array}{l}\text { Supplier } 3 \text { cannot supply raw materials on } \\
\text { the scheduled time or is destroyed by disasters. }\end{array}$ & Parts $5 \& 6$ & 2 & 2 & $16 \%$ \\
\hline $\mathrm{H}_{4}$ & $\begin{array}{l}\text { Supplier } 4 \text { cannot supply raw materials on the } \\
\text { scheduled time or is destroyed by disasters. }\end{array}$ & Parts $3 \& 4$ & 1 & 3 & $12 \%$ \\
\hline $\mathrm{H}_{5}$ & $\begin{array}{l}\text { Supplier } 5 \text { cannot supply raw materials on the } \\
\text { scheduled time or is destroyed by disasters. }\end{array}$ & Parts $3 \& 4$ & 1 & 5 & $20 \%$ \\
\hline $\mathrm{H}_{6}$ & $\begin{array}{l}\text { Supplier } 6 \text { cannot supply raw materials on } \\
\text { the scheduled time or is destroyed by disasters. }\end{array}$ & Parts $3 \& 4$ & 1 & 3 & $12 \%$ \\
\hline $\mathrm{H}_{7}$ & $\begin{array}{l}\text { Supplier } 7 \text { cannot supply raw materials on } \\
\text { the scheduled time or is destroyed by disasters. }\end{array}$ & Parts $1 \& 2$ & 2 & 1 & $8 \%$ \\
\hline $\mathrm{H}_{8}$ & $\begin{array}{l}\text { Supplier } 8 \text { cannot supply raw materials on } \\
\text { the scheduled time or is destroyed by disasters. }\end{array}$ & Parts $3 \& 4$ & 1 & 2 & $8 \%$ \\
\hline $\mathrm{H}_{9}$ & $\begin{array}{l}\text { Supplier } 9 \text { cannot supply raw materials on the } \\
\text { scheduled time or is destroyed by disasters. }\end{array}$ & Parts $5 \& 6$ & 1 & 2 & $8 \%$ \\
\hline $\mathrm{H}_{10}$ & $\begin{array}{l}\text { Supplier } 10 \text { cannot supply raw materials on the } \\
\text { scheduled time or is destroyed by disasters. }\end{array}$ & Parts $3 \& 4$ & 1 & 3 & $12 \%$ \\
\hline $\mathrm{H}_{11}$ & $\begin{array}{l}\text { Supplier } 11 \text { cannot supply raw materials on } \\
\text { the scheduled time or is destroyed by disasters. }\end{array}$ & Parts $3 \& 4$ & 1 & 3 & $12 \%$ \\
\hline $\mathrm{H}_{12}$ & $\begin{array}{l}\text { End customer demand is higher than } \\
\text { forecasted demand. }\end{array}$ & All product & 1 & 5 & $20 \%$ \\
\hline $\mathrm{H}_{13}$ & $\begin{array}{l}\text { End customer demand is lower } \\
\text { than forecasted demand. }\end{array}$ & All product & 1 & 5 & $20 \%$ \\
\hline
\end{tabular}

According to (Bogataj and Bogataj, 2007), risk can be assessed by two common approaches: the likelihood of the occurrence of an (undesirable) event and the negative implications of this event. Risk Likelihood captures the probabilities associated with disruption risks in the supply chain. Respondents reported on a risk which had already been experienced in the past, they were asked to report on the degree of likelihood of its reoccurrence (Bovell, 2012). The risk impact also depends on some factors such as the percentage of raw materials cost and its effect on the total cost of required raw materials. Therefore, the total risk score can be calculated by multiplying those scores together.

The risks $\mathrm{H}_{1}, \mathrm{H}_{2}, \mathrm{H}_{3}, \mathrm{H}_{4}, \mathrm{H}_{5}, \mathrm{H}_{2}, \mathrm{H}_{6}, \mathrm{H}_{7}, \mathrm{H}_{8}, \mathrm{H}_{9}, \mathrm{H}_{10}$ and $\mathrm{H}_{11}$ might result from increasing the lead time of raw materials of external suppliers $\mathrm{S}_{\mathrm{E} 1}, \mathrm{~S}_{\mathrm{E} 2}, \mathrm{~S}_{\mathrm{E} 3}, \mathrm{~S}_{\mathrm{E} 4}$, $\mathrm{S}_{\mathrm{E} 5}, \mathrm{~S}_{\mathrm{E} 6}, \mathrm{~S}_{\mathrm{E} 7}, \mathrm{~S}_{\mathrm{E} 8}, \mathrm{~S}_{\mathrm{E} 9}, \mathrm{~S}_{\mathrm{E} 10}$ and $\mathrm{S}_{\mathrm{E} 11}$ respectively to arrive at the manufacturing industry at the planned time. The likelihood of the occurrence for such risks might arise as a result of some factors such as natural and man-made disasters and economic crises (currency valuation/ strikes). $\mathrm{H}_{12}$ may arise from the lack of raw materials that are ordered from the external suppliers to the production system, which might have resulted from some factors such as increasing customer demand in the marketplace and the inventory elimination by implementing JIT system within the production facility. The likelihood of its occurrence is low and its impact on the production system will be mostly high. Finally, $\mathrm{H}_{13}$ may arise from the lack of customer demand in the marketplace which will incur a holding cost for the production facility by keeping the final products within its warehouses. The likelihood of its occurrence also is almost low and its impact on the production system will be high.

\section{RESULTS AND DISCUSSION}

The results of testing the proposed model was used to ascertain the effect of decision variables on other parameters examined within the production system. By using the mentioned external and local suppliers $\left(\mathrm{N}_{\mathrm{SE}}=\right.$ 11 and $\mathrm{N}_{\mathrm{SLB}}=7$ ) for supplying raw materials to produce the final product in the production system, many disruptions might be occurred within the supply chain. It is assumed that if external supplier $\mathrm{j}$ has disruption, then $S_{E j}=0$ otherwise, $S_{E j}=1$ and the same for the local 
suppliers. The findings of this research are organised in three cases as follows.

\section{Case I}

This case addresses the analysis of model results analysis in different cases for the occurrence of external suppliers' disruptions using different levels of decision variables. By way of choosing twenty of these disruptions randomly as a case study to evaluate the performance of the developed model, the obtained results of total cost of the final product and its components are shown in Fig. 3. This means that the selected local backup suppliers will be used for procuring raw materials instead of the disrupted external suppliers.

As seen from the results achieved as shown in Fig. 3, the raw materials quantity procured from the used suppliers (external/local), customer demand, lead time required to raw materials be received to the production facility and the transportation mode used for transporting raw materials to the production system have a significant impact on the total cost of the final product. In the case of any disruption occurrence, it is clear that by changing each decision variable, the result is different. In the case of all external suppliers are disrupted using the highest levels of the used decision variables, it is found that $\mathrm{CP}$ is the highest rate compared with the other disruptions. That is based on the local suppliers' reliability. However, Ctr relatively, is the lowest as a result of the cost results from transporting raw materials from their origins to the production system that is low. The impact of these disruptions on the related costs of the final product can also be very clearly seen in Fig. 3.

\section{Case II}

In this sub-suction, it is an analysis of the effects of the used decision variables in the event of some disruptions occurrence using the same levels of decision variables on the disrupted external suppliers are analysed. Figure 4 illustrates computational results for twenty cases of expected disruptions, which were selected at random. These findings and their impacts on the production cost can be clearly seen in Fig. 4 .

Also, comparison between the case wherein all external suppliers are able to supply their raw materials to the production system and the case in which all suppliers have disruption were prepared as shown in Fig. 5. This Figure illustrates the effects of these disruptions on the cost types, which will affect the total cost required to produce the final product.

It is clear that, using the local backup suppliers to supply raw materials to the production system, the total cost is higher than if the external suppliers are used for this purpose. In addition, it is concluded that $C_{P}$ and $C_{R}$ in the case of all suppliers having disruption are higher than the other case. However, $\mathrm{C}_{\mathrm{H}}, \mathrm{C}_{\mathrm{tr}}, \mathrm{TP}$ and $\mathrm{C}_{\mathrm{D}}$ are the lowest.

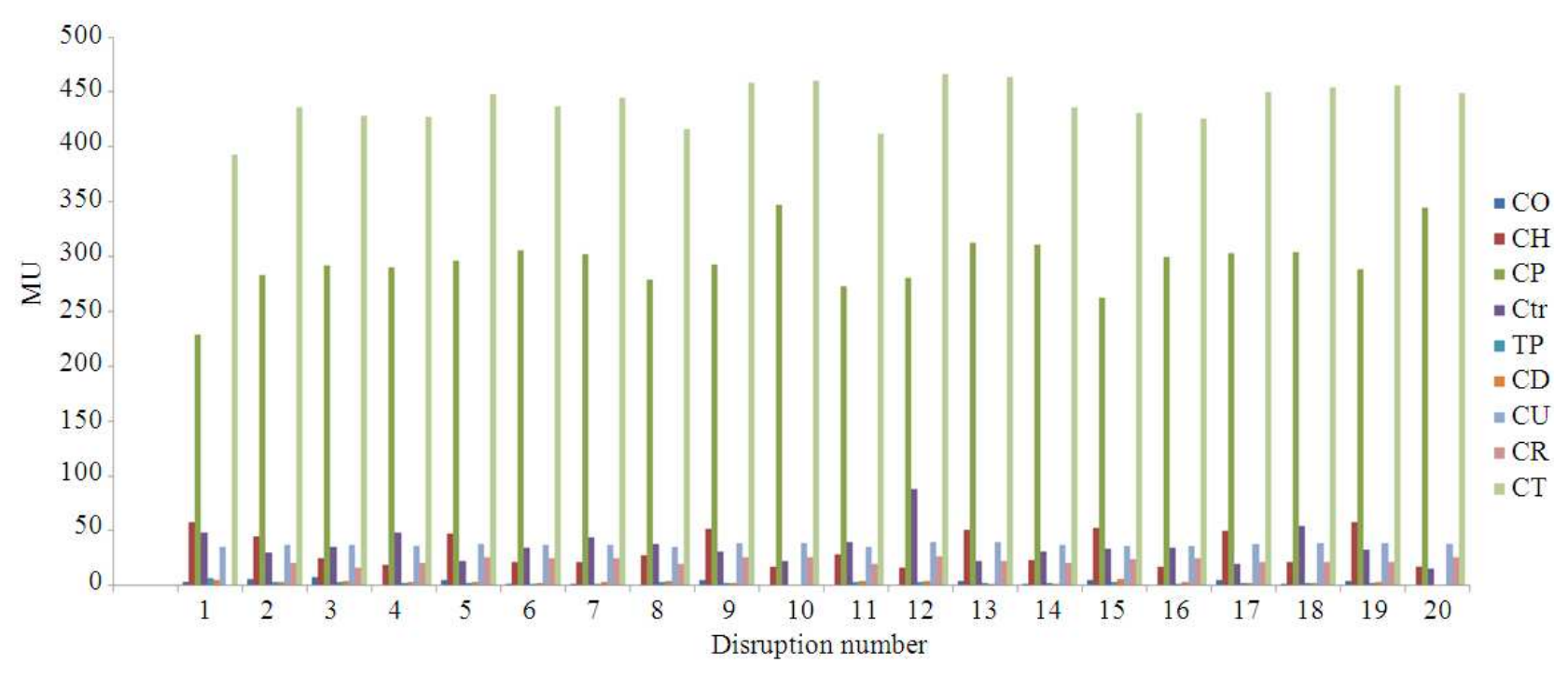

Fig. 3. Impact of some expected disruptions on external suppliers using different variables levels 


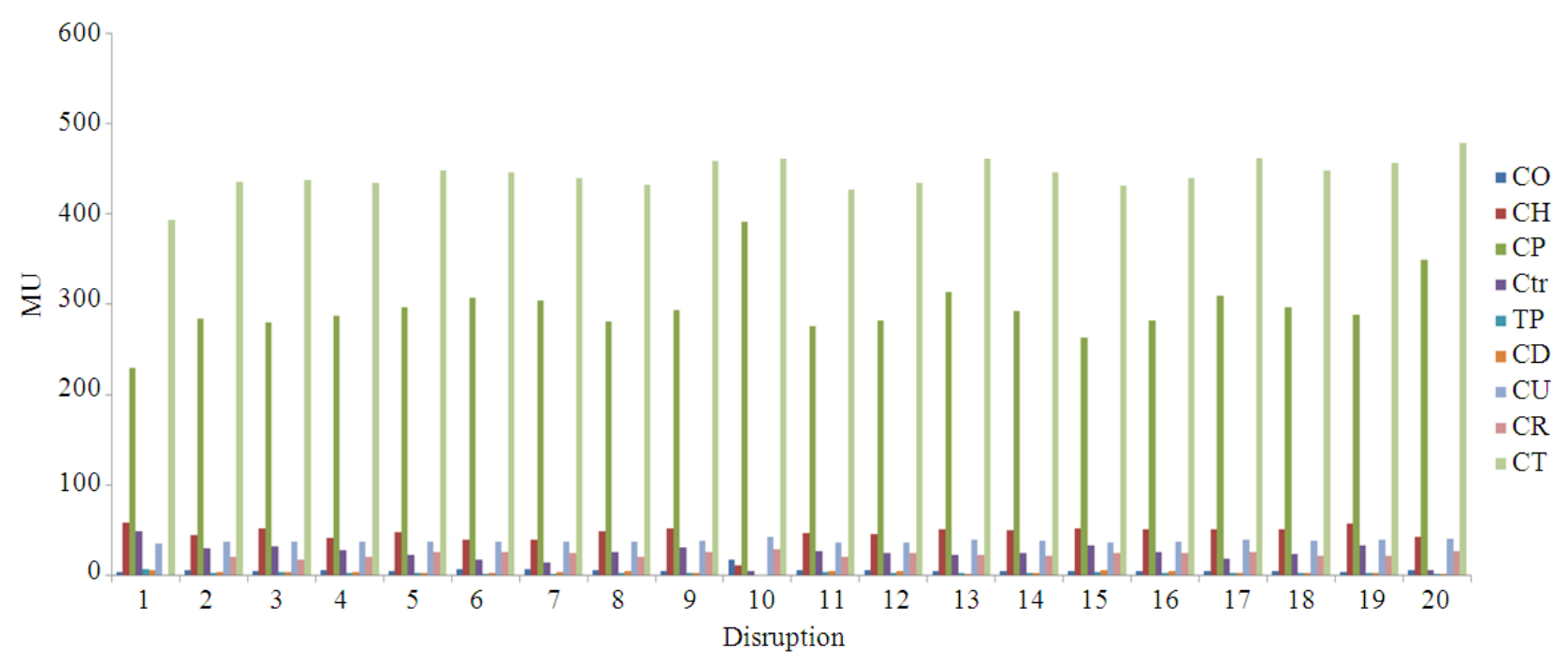

Fig. 4. Impact of some expected disruptions on the related costs using the same variables levels

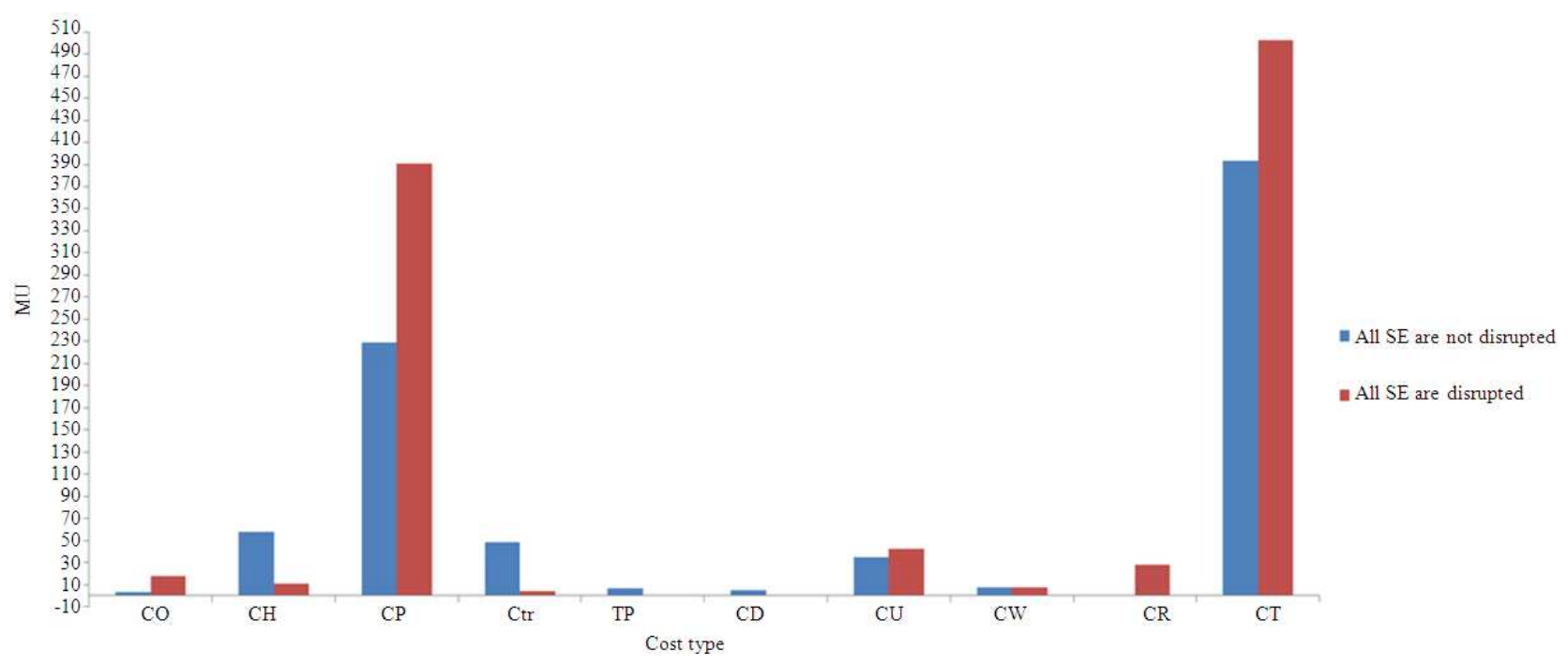

Fig. 5. Cost types comparison between the external suppliers are (1) not disrupted (2) disrupted

\section{Case III}

To define the effects of each decision variable on the total cost of the final product, the second disruption, which is $\left(\mathrm{S}_{\mathrm{E} 1}=1, \mathrm{~S}_{\mathrm{E} 2}=0, \mathrm{~S}_{\mathrm{E} 3}=1, \mathrm{~S}_{\mathrm{E} 4}=0, \mathrm{~S}_{\mathrm{E} 5}=1, \mathrm{~S}_{\mathrm{E} 6}=0, \mathrm{~S}_{\mathrm{E} 7}=\right.$ $1, \mathrm{~S}_{\mathrm{E} 8}=0, \mathrm{~S}_{\mathrm{E} 9}=1, \mathrm{~S}_{\mathrm{E} 10}=0, \mathrm{~S}_{\mathrm{E} 11}=1$ ) was selected for this purpose. By changing the used decision variables levels $\left(\mathrm{Q}_{\mathrm{RM}}, \mathrm{d}_{\mathrm{P}}, \mathrm{LT}\right.$ and $\left.\mathrm{t}_{\mathrm{m}}\right)$, the total cost of the product will be changed depending on the effect of each variable as shown in Fig. 6. The findings illustrated that the highest rate of the total cost is highlighted using $Q_{R M}=2450, d_{p}=$
140 and 210 and $t_{m}=4$. The main affected cost components are $\mathrm{C}_{\mathrm{tr}}$, which depends on the transportation mode used for transporting raw materials from the suppliers (external/local) to the production system; $\mathrm{C}_{\mathrm{U}}$ that is considered as a percentage rate of some costs types which was mentioned previously; as well as $C_{R}$ arising from the used suppliers. These findings demonstrate that the use of different levels of decision variables in case of any disruption occurrence have direct impacts on the total cost arising from producing final product within the production system. 


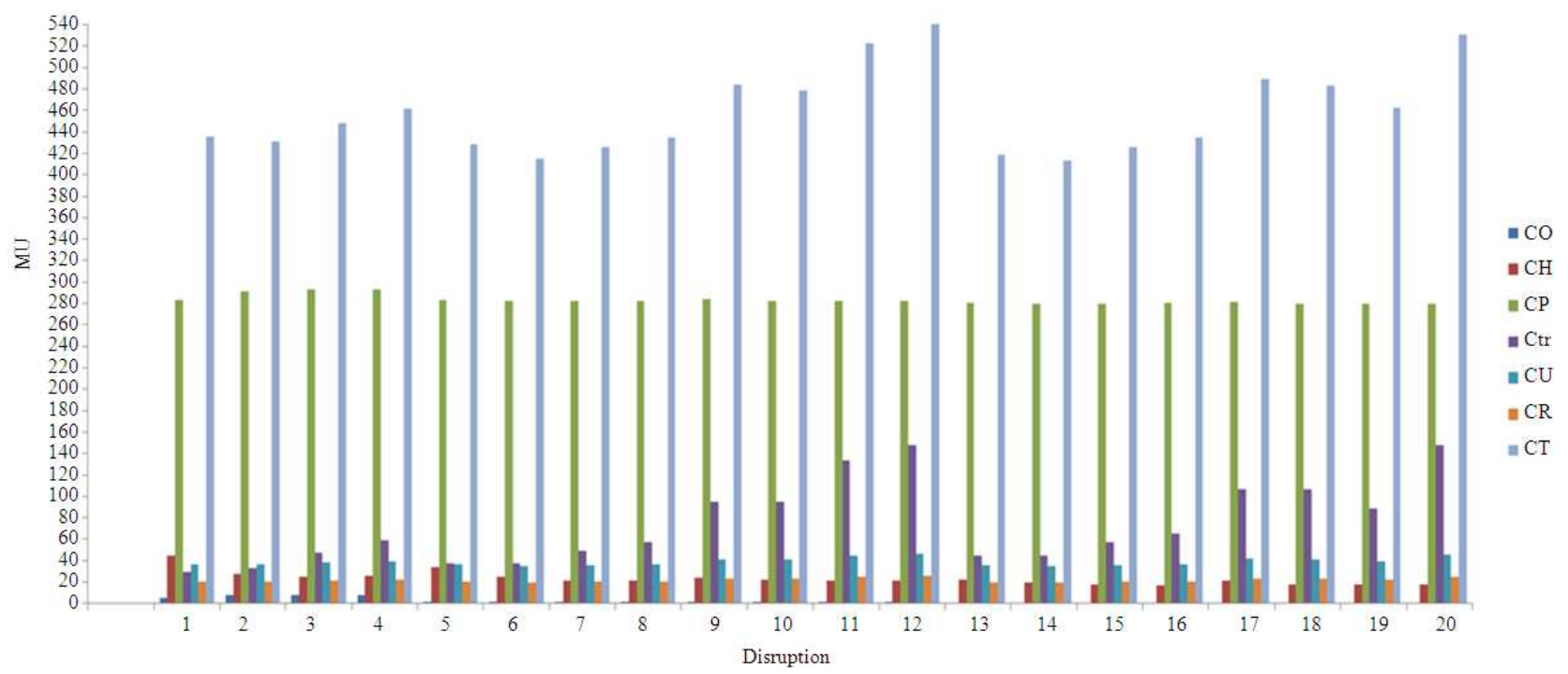

Fig. 6. Effects of decision variables on the related costs of the final product in a case of external suppliers disruptions using different levels of variables

\section{COCLUSION}

This study presented a mathematical model for a simultaneous cost-risk reduction in JIT systems. It was developed to determine an optimal strategy for supplying raw materials to the production systems by using regular multi-external and local backup suppliers in case of the occurrence of likely disruption such as natural and manmade disasters and economic crises. The developed model consists of the formulation of the corresponding objective function of minimising the total costs of the final product in the production system and the risks arising from these benefits. The total cost includes raw material, worker, utilities and risk costs.

The mathematical model was coded by using JAVA. In this program, each cost component is coded individually and the total cost of the final product equals the summation of these components outcomes. The decision variables levels were selected to validate the objective functions achieved by this study for simultaneous cost-risk reduction in JIT systems. To authenticate the performance of the developed model, a simplified example is presented in this study. The results achieved from the developed model were compared with the results obtained from the Microsoft Excel program to verify that the model was designed with sufficient accuracy. As they were almost the same, the computer programming was successfully validated. Comparing the use of local backup suppliers for supplying raw materials to the production facility in JIT systems with the use of external suppliers had a significant impact on the total cost of final product. However, this increase can lead to other benefits such as preserving the reputation of the production facility intact with end-user. Thereby, JIT principles can be effectively applied for satisfying customer requirements at a minimum profit with a minimum level of risk. In future research, the developed mathematical model will be considered for optimization purposes using Genetic Algorithms.

\section{REFERENCES}

An, C. and H. Fromm, 2005. Supply Chain Management on Demand: Strategies and Technologies, Applications. 1st Edn., Springer, Berlin, ISBN-10: 3540273549, pp: 350.

Bogataj, D. and M. Bogataj, 2007. Measuring the supply chain risk and vulnerability in frequency space. Int. J. Product. Econ., 108: 291-301. DOI: 10.1016/j.ijpe.2006.12.017

Bovell, L., 2012. Joint resolution of supply chain risks: The role of risk characteristics and problem solving approach. Georgia State University.

BW, 2011. Thailand Flooding Causes Property Damage, Supply Chain Losses for Businesses. Business Wire. 
Canel, C. and B.M. Khumawala, 2001. International facilities location: A heuristic procedure for the dynamic uncapacitated problem. Int. J. Product. Res., 39: 3975-4000. DOI: 10.1080/00207540110069096

Carneiro, M.C., G.P. Ribas and S. Hamacher, 2010. Risk management in the oil supply chain: A CVaR approach. Indus. Eng. Chem. Res., 49: 3286-3294. DOI: $10.1021 / \mathrm{ie} 901265 \mathrm{n}$

Chen, L., 2011. Fair sharing of costs and revenue through transfer pricing in supply chains with stochastic demand. Kent State University and OhioLINK.

Chen, Z. and B. Sarker, 2009. Multi-vendor integrated procurement-production system under shared transportation and just-in-time delivery system. J. Operat. Res. Soc., 61: 1654-1666. DOI: 10.1057/jors.2009.115

Chopra, S. and P. Meindl, 2010. Supply Chain Management. 4th Edn., Pearson Education India, Upper Saddle River, N.J., ISBN-10: 8131730719, pp: 578.

El Dabee, F., R. Marian and Y. Amer, 2012. An optimization model for a simultaneous cost-risk reduction in just-in-time systems. Proceedings of the 11th Global Congress on Manufacturing and Management, (MM '12), pp: 190-201.

El Dabee, F., R. Marian and Y. Amer, 2013a. Development of a model for simultaneous cost-risk reduction in JIT systems using multi-external and local backup suppliers. Automat. Control Intell. Syst., 1: 42-52. DOI: 10.11648/j.acis.20130103.12

El Dabee, F., R. Marian and Y. Amer, 2013b. A novel model for simultaneously minimising costs and risks in just-in-time systems using multi-backup suppliers: Part 1-modelling. World Acad. Sci. Eng. Technol., 74: 332-337.

Eldenburg, L., 2007. Cost Management: Measuring Monitoring and Motivating Performance. 1st Edn., John Wiley and Sons, ISBN-10: 8126511451, pp: 756.

Fahimnia, B., L. Luong and R. Marian, 2008. An integrated model for the optimization of a twoechelon supply network. J. Ach. Mater. Manufact. Eng., 31: 477-484.

Fahimnia, B., R. Marian and B. Motevallian, 2009. Analysing the hindrances to the reduction of manufacturing lead-time and their associated environmental pollution. Int. J. Environ. Technol. Manage., 10 : 16-25. DOI: 10.1504/IJETM.2009.021574
Gaivoronski, A.A., G.M. Sechi and P. Zuddas, 2012. Balancing cost-risk in management optimization of water resource systems under uncertainty. Phys. Chem. Earth, 42-44: 98-107. DOI: 10.1016/j.pce.2011.05.015

Ha, D. and S. Kim, 1997. Implementation of JIT purchasing: An integrated approach. Product. Plann. Control, 8: 152-157. DOI: 10.1080/095372897235415

Ho, L. and W. Kao, 2013. Applying a just-in-time integrated supply chain model with inventory and waste reduction. Am. J. Applied Sci., 10: 751-759. DOI: 10.3844/ajassp.2013.751.759

Hokoma, R., M. Khan and K. Hussain, 2008. Investigation into the implementation stages of manufacturing and quality techniques and philosophies within the Libyan cement industry. J. Manufact. Technol. Manage., 19: 893-907. DOI: 10.1108/17410380810898804

Hokoma, R., M. Khan and K. Hussain, 2010. The present status of quality and manufacturing management techniques and philosophies within the Libyan iron and steel industry. TQM J., 22: 209-221. DOI: 10.1108/17542731011024309

Jaggi, C.K. and N. Arneja, 2011. Periodic inventory model with reduced setup cost under service level constraint. Electr. J. Applied Stat. Anal., 4: 111-123. DOI: 10.1285/i20705948v4n2,

Jose, G., 2011. Modelling risk and innovation management. Adv. Competitiveness Res., 19: 45-57.

Khan, L.R. and R.A. Sarker, 2002. An optimal batch size for a JIT manufacturing system. Comput. Indus. Eng., 42: 127-136. DOI: 10.1016/S03608352(02)00009-8

Krausmann, E. and A. Cruz, 2013. Impact of the 11 March 2011, great East Japan earthquake and tsunami on the chemical industry. Natural Hazards, 67: 811-828. DOI: 10.1007/s11069-013-0607-0

Lababidi, H., M. Ahmed, I. Alatiqi and A. Al-Enzi, 2004. Optimizing the supply chain of a petrochemical company under uncertain operating and economic conditions. Ind. Eng. Chem. Res., 43: 63-73. DOI: 10.1021/ie030555d

Li, Y., K. Man, K. Tang, S. Kwong and W. Ip, 2000. Genetic algorithm to production planning and scheduling problems for manufacturing systems. Product. Plann. Control, 11: 443-458. DOI: 10.1080/09537280050051942 
Mohd-Lair, N.A., 2008. An integrated model for optimising manufacturing and distribution network scheduling. PhD Thesis, University of South Australia.

Monden, Y., 2000. Japanese Cost Management. 1st Edn., World Scientific, London, ISBN-10: 1860941850 , pp: 490.

Rawabdeh, I., 2005. A model for the assessment of waste in job shop environments. Int. J. Operat. Product. Manage., 25: 800-822. DOI: 10.1108/01443570510608619

Sarker, R. and L. Khan, 1999. An optimal batch size for a production system operating under periodic delivery policy. Comput. Indus. Eng., 37: 711-730. DOI: $10.1016 / \mathrm{S} 0360-8352(00) 00006-1$
Simchi-Levi, D., L. Snyder and M. Watson, 2002. Strategies for Uncertain Times. Supply Chain Mange. Rev.

Tomlin, B., 2009. Disruption-management strategies for short life-cycle products. Naval Res. Logist., 56: 318-347. DOI: $10.1002 /$ nav.20344

Tourki, T., 2010. Implementation of lean within the cement industry. $\mathrm{PhD}$ Thesis, De Montfort University, Leicester.

Yang, J. and J. Pan, 2004. Just-in-time purchasing: An integrated inventory model involving deterministic variable lead time and quality improvement investment. Int. J. Product. Res., 42: 853-863. DOI: 10.1080/00207540310001632448 